\title{
Well-Ordered Mesoporous Carbon Thin Film with Perpendicular Channels: Application to Direct Methanol Fuel Cell
}

\author{
Meng-Liang Lin, ${ }^{\dagger}$ Chun-Chieh Huang, ${ }^{\ddagger}$ Man-Yin Lo, ${ }^{\ddagger}$ and Chung-Yuan Mou $*, \dagger$ \\ Department of Chemistry, National Taiwan University, Taipei 106, Taiwan, and Material and Chemical \\ Research Laboratories, Industrial Technology Research Institute, Hsinchu 300, Taiwan
}

Received: August 22, 2007; In Final Form: October 25, 2007

\begin{abstract}
Ordered mesoporous thin film carbon (TFC) material, of short channels vertical to the film, was synthesized by the replication of mesoporous silica SBA-15( $\perp$ ) template and was deposited with PtRu nanocatalyst as an anodic material in direct methanol fuel cell (DMFC). The anode nanocatalyst PtRu was characterized by XRD, Raman, XPS, nitrogen adsorption, and $\mathrm{CO}_{\mathrm{ad}}$ stripping. Electrocatalytic activity, characterized by anodic current, was compared with PtRu supported on various carbon supports, including TFC, CMK-3, and XC-72. The much enhanced methanol electrochemical oxidation activity in PtRu/TFC was ascribed to increased nanocatalysts' utilization efficiency with the short nanochannels of TFC.
\end{abstract}

\section{Introduction}

Designing 3-D nanostructured porous carbon materials for electrocatalysis is important for high performance electrochemical devices such as a fuel cell or battery. Careful construction of the porous carbon supported catalysts for facile molecular transport of reactants and products, good electronic conductivity, high surface reactivity, electronic conductivity, and ionic conductivity would enhance the molecular conversion. ${ }^{1}$ Thus nanoarchitectures of the electrocatalyst designed and fabricated from the appropriate nanoscale building blocks would be very welcome.

Nanostructured carbon materials synthesized by casting manipulation of ordered porous silica templates ${ }^{2-3}$ are of great interest in many applications such as catalyst supports ${ }^{4}$ and adsorbents. ${ }^{5}$ Ordered mesoporous carbon (OMC) has the advantages of high surface area, tunable pore size, interconnected pore network, and tailorable surface properties. ${ }^{6-9}$ Recently, OMC as support for metal nanocatalysts for electrode materials in low-temperature fuel cells has been attracting much attention. ${ }^{10,11}$

Ordered mesoporous carbon (OMC) may be obtained by replicating a well-ordered mesoporous silica. ${ }^{12}$ The CMK-3 mesoporous carbon, templated from SBA-15, possesses a structure of a hexagonally assembled array of interconnected long carbon rods (usually more than $500 \mathrm{~nm}$ ). With the deposition of Pt or Pt-based nanoparticles on its internal and external surfaces, the materials have been used as the electrode materials in direct methanol fuel cell (DMFC). ${ }^{13,14}$ Methanol electrochemical oxidation has been examined. However, no significantly higher performance than the commercial catalysts has been found for OMC supported catalysts. Though displaying high surface area and well-controlled porosity, the dispersion and utilization of nanocatalysts inside the long pore channel of CMK-3 might not be efficient. Owing to the bulky morphology of typical OMC, the transportation of fuel and products in the nanospace could be rather inefficient. Eliminating the transport

* Corresponding author. E-mail: cymou@ntu.edu.tw.

National Taiwan University.

$\doteqdot$ Industrial Technology Research Institute.

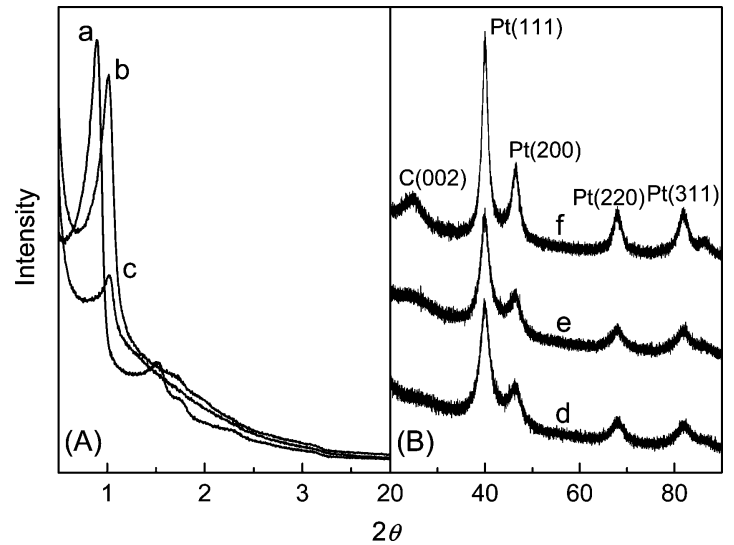

Figure 1. (A) Low-angle XRD patterns of (a) SBA-15( $\perp$ ) silica, (b) TFC carbon, and (c) PtRu20/TFC. (B) Wide-angle XRD patterns of (d) PtRu20/TFC, (e) PtRu20/CMK-3, and (f) PtRu20/XC-72.

hindrance effect caused by long distance migration or structure blockage of fuel molecules is a problem that needs to be solved. It is the purpose of this paper to present a novel OMC framework with very short nanochannels to increase the dispersion of the catalyst and to facilitate the transport of reactants and products. The new electrode carbon material is based on the mesoporous carbon CMK-3 of film morphology with very short channels (less than $100 \mathrm{~nm}$ ) perpendicular to the film surface. The thin film morphology will simultaneously improve its electric contact with the electrode surface and the mass transport of the reactants in and out of the short channels where PtRu nanoparticles are confined.

Only limited studies had been focused on well-ordered mesoporous carbon thin film. ${ }^{15}$ Previously, we reported a wellordered mesoporous silica SBA-15 $(\perp)$ thin film with perpendicular channels obtained by using a ternary surfactant system $\mathrm{C}_{16}$ TMAB/SDS/P123 as template and hydrothermal processes. ${ }^{16}$ In this work, well-ordered mesoporous carbon materials with perpendicular channels were obtained by replicating the corresponding mesoporous silica platelets SBA-15( $\perp$ ) template. ${ }^{16}$ OMC materials with distinctive thin film morphology were obtained and used as supports for PtRu bimetallic nanocatalysts 
SCHEME 1: Syntheses of Mesoporous Thin Film Carbon (TFC) and Carbon Supported with PtRu Nanocatalysts (PtRu/TFC)

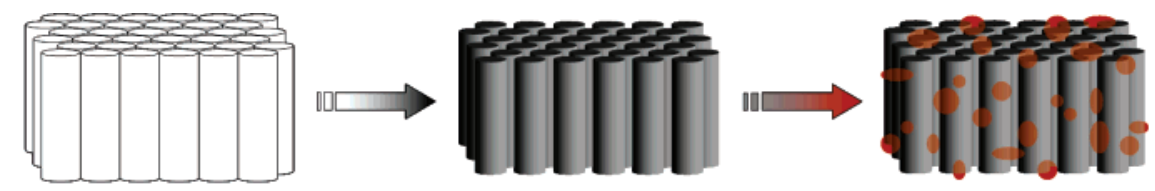

SBA-15 $(\perp)$ Silica Template

Thin Film Carbon (TFC)

Thin Film Carbon with PtRu Nanocatalysts (PtRu/TFC)

in the electrochemical oxidation of methanol. In Scheme 1, we illustrate the ordered mesoporous thin film carbon (TFC) material of short channels vertical to the film. It was synthesized by the replication of the mesoporous silica SBA-15 $(\perp)$ template and was deposited with PtRu nanocatalyst as an anodic material in a direct methanol fuel cell (DMFC). The much enhanced methanol electrochemical oxidation activity in PtRu/TFC resulted from increased metal active sites and fuel molecules permeability provided by the special three-dimensional construction of the thin film carbon (TFC).

\section{Experimental Section}

Syntheses. The mesoporous silica SBA-15( $\perp$ ) was synthesized according to our previously reported method. ${ }^{16}$ A $0.75 \mathrm{~g}$ sample of $\mathrm{C}_{16} \mathrm{TMAB}$ (Acrôs), $1.00 \mathrm{~g}$ SDS (Aldrich), and 0.70 g Pluronic 123 (Aldrich) were mixed in $50 \mathrm{~mL}$ of $\mathrm{H}_{2} \mathrm{O}$ under stirring at $45^{\circ} \mathrm{C}$ to form a cloudy solution. Then the mixture was directly poured into a $150 \mathrm{~mL}$ dilute solution of sodium silicate (Aldrich), with $\left[\mathrm{SiO}_{2}\right]=80.0 \mathrm{mM}$, at $\mathrm{pH} \approx 5.0$. The precipitates formed within seconds were hydrothermally treated at $100{ }^{\circ} \mathrm{C}$ for $24 \mathrm{~h}$, filtered, washed with $\mathrm{H}_{2} \mathrm{O}$, and calcined at $560{ }^{\circ} \mathrm{C}$ for $6 \mathrm{~h}$.

A $0.5 \mathrm{~g}$ sample of mesoporous silica SBA-15( $\perp)$ template was added into a solution composed of $0.625 \mathrm{~g}$ sucrose (Acrôs), $0.07 \mathrm{~g} \mathrm{H}_{2} \mathrm{SO}_{4}$, and $5 \mathrm{~g} \mathrm{H}_{2} \mathrm{O}$. After stirring for $1 \mathrm{~h}$, the mixture was dried at $100{ }^{\circ} \mathrm{C}$ for $6 \mathrm{~h}$ and then at $160{ }^{\circ} \mathrm{C}$ for another $6 \mathrm{~h}$. With further addition of $0.4 \mathrm{~g}$ sucrose, $0.045 \mathrm{~g} \mathrm{H}_{2} \mathrm{SO}_{4}$, the sample was treated again at 100 and $160{ }^{\circ} \mathrm{C}$. The carbonization was completed with the heating rate at $2.5{ }^{\circ} \mathrm{C} / \mathrm{min}$, and the sample was kept at $900{ }^{\circ} \mathrm{C}$ for $6 \mathrm{~h}$ under $\mathrm{N}_{2}(\mathrm{~g})$ condition. The silica content was then dissolved with 10 wt $\%$ hydrogen fluoride solution, thus recovering the denoted TFC carbon product. In addition, a normal type CMK-3 carbon material was synthesized by following Ryoo's method. ${ }^{11}$

PtRu nanocatalysts were synthesized and deposited on carbon supports by using a wet chemical reduction method. ${ }^{17}$ Briefly, $0.1 \mathrm{~g}$ TFC carbon material was added in a solution containing a desired amount of $0.01 \mathrm{M} \mathrm{H}_{2} \mathrm{PtCl}_{6}$ (Acrôs) and $0.01 \mathrm{M} \mathrm{RuCl}_{3}$ (Aldrich). The mixture was stirred for $30 \mathrm{~min}$, and an excess of $0.1 \mathrm{M} \mathrm{NaBH}_{4}$ (Aldrich) solution was added into the mixture drop by drop. After stirring for $1 \mathrm{~h}$, the solid was recovered by centrifugation and extensively washed with $\mathrm{H}_{2} \mathrm{O}$.

Electrochemical Activity Tests. The electrochemical activity measurements were carried out by cyclic voltammetry (CV) using an Autolab PGSTAT 30 potentiostat equipped with a rotatory disk electrode (RDE). ${ }^{18}$ A conventional three-compartment electrochemical cell consisting of glassy carbon (GC) electrode with an area of $0.196 \mathrm{~cm}^{2}$ as the working electrode, Pt flat as the counter electrode, and reference hydrogen electrode (RHE) as the reference electrode was used. The GC electrode was polished to a mirror finish with a $0.05 \mu \mathrm{m}$ alumina suspension before each experiment. The catalyst ink was prepared by adding $5 \mathrm{mg} 20 \mathrm{wt} \% \mathrm{PtRu} / \mathrm{C}$ sample in $2.5 \mathrm{~mL}$ of $\mathrm{H}_{2} \mathrm{O}$ and ultrasonically dispersed for $30 \mathrm{~min}$. Then, a $20 \mu \mathrm{L}$ suspension was pipetted onto the top surface of a GC electrode followed by $60^{\circ} \mathrm{C}$ drying for $1 \mathrm{~h}$ in air. Thus we obtained a PtRu metal loading as $0.04 \mathrm{mg} / \mathrm{cm}^{2}$ on the working electrode. After the electrode was cooled down, $20 \mu \mathrm{L}$ of $1 \mathrm{wt} \%$ Nafion solution was pipetted onto the ink surface. The CV curves of methanol electrochemical oxidation were measured in $0.5 \mathrm{M}$ $\mathrm{H}_{2} \mathrm{SO}_{4}$ and $1.0 \mathrm{M} \mathrm{CH}_{3} \mathrm{OH}$ solution and characterized by the steady-state current density of the tenth $\mathrm{CV}$ sweep at $0.5 \mathrm{~V}$. The scan rate is $10 \mathrm{mV} / \mathrm{s}$. The measurements were carried out at $60{ }^{\circ} \mathrm{C}$ with the working electrode rotated in $1600 \mathrm{rpm}$. CO stripping voltammogram curves were collected by linear sweep voltammetry (LSV) in a three-electrode cell. ${ }^{19}$ First, $\mathrm{N}_{2}$ gas was purged into $0.5 \mathrm{M} \mathrm{H}_{2} \mathrm{SO}_{4}$ solution for $30 \mathrm{~min}$. Then, $99.9 \%$ carbon monoxide (CO) gas was purged into $0.5 \mathrm{M} \mathrm{H}_{2} \mathrm{SO}_{4}$ solution for $15 \mathrm{~min}$ to allow complete adsorption of $\mathrm{CO}$ onto the catalyst surface while maintaining a working electrode potential at $0.2 \mathrm{~V}$. The excess $\mathrm{CO}$ in the solution was removed by bubbling $\mathrm{N}_{2}$ gas for another $30 \mathrm{~min}$ by holding the potential at $0.2 \mathrm{~V}$. Finally, the stripping voltammograms were done between 0.2 and $1.0 \mathrm{~V}$ in $0.5 \mathrm{M} \mathrm{H}_{2} \mathrm{SO}_{4}$ solution with scan rate of $10 \mathrm{mV} / \mathrm{s}$ at $60{ }^{\circ} \mathrm{C}$.

Characterizations. The powder X-ray diffraction (XRD) patterns were collected on a PANalytical X'Pert PRO instrument operating at a $45 \mathrm{kV}$ and a current of $40 \mathrm{~mA}$ with $\mathrm{Cu} \mathrm{K} \alpha(\lambda=$ $1.5406 \AA$ A) radiation. Nitrogen adsorption-desorption isotherms were obtained at $-196{ }^{\circ} \mathrm{C}$ on a Micromeritics ASAP 2010 apparatus. The specific surface area of the samples was calculated according to the Brunauer-Emmett-Teller (BET) method, and the pore size distribution curves were obtained from the analysis of nitrogen adsorption isotherms using the BarrettJoyner-Halenda (BJH) method. Transmission electron microscopy (TEM) images were obtained using a Hitachi H-7100 instrument with an operating voltage of $75 \mathrm{kV}$. The fieldemission scanning electron microscopy (FE-SEM) image was conducted by JEOL, JSM-6700F microscope operating at 10 $\mathrm{kV}$. X-ray photoelectron spectroscopy (XPS) measurements were performed with a Thermo VG Scientific, ESCALAB 250 equipped with an $\mathrm{Al} \mathrm{K} \alpha$ radiation source (1486.6 $\mathrm{eV}$ ) under a residual pressure of $\sim 1 \times 10^{-9}$ Torr. The measured spectra were deconvoluted by a least-squares procedure to a product of Gaussian-Lorentzian functions after background subtraction by using the software XPSPEAK.

\section{Results and Discussions}

By impregnating carbon supports with $\mathrm{H}_{2} \mathrm{PtCl}_{6}$ and $\mathrm{RuCl}_{3}$ and reduced chemically with $\mathrm{NaBH}_{4}, \mathrm{PtRu}$ bimetallic alloy nanoparticles were homogeneously dispersed onto the external and internal surfaces of mesoporous carbon. Figure 1 (A) shows the low-angle XRD patterns of SBA-15 $(\perp)$ mesoporous silica template and its carbon replica TFC. The SBA-15 $(\perp)$ silica showed well-resolved peaks which are assigned as the (100), (110), (200), and (210) diffractions of the two-dimensional hexagonal $(p 6 \mathrm{~mm})$ structure. The TFC materials also showed three diffraction peaks (100), (110), and (200) but shifted to 


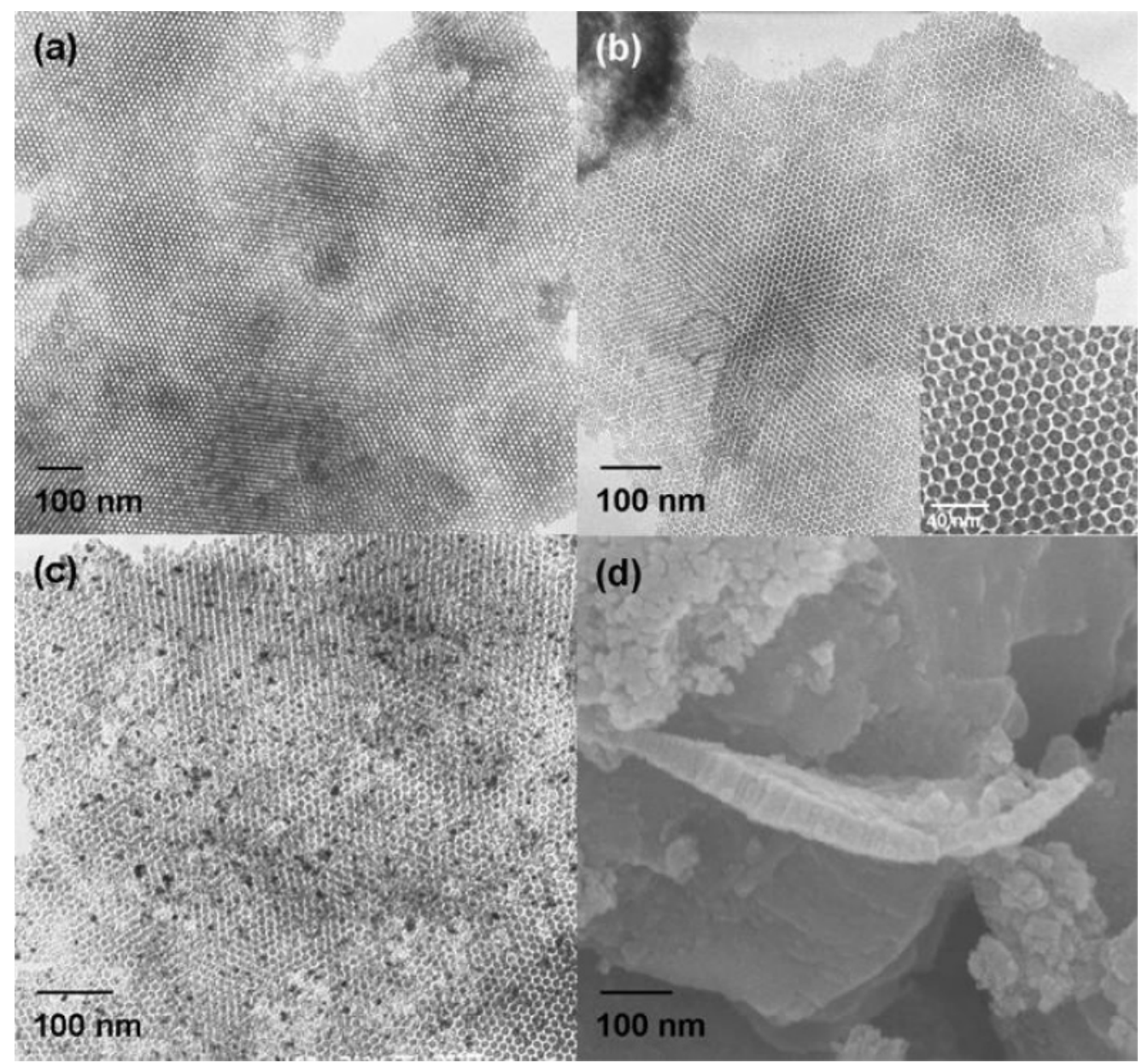

Figure 2. TEM images of (a) SBA-15( $\perp$ ) silica, (b) TFC carbon, (c) PtRu20/TFC, and (d) the FE-SEM image of TFC carbon.

higher angles, resulting from structure shrinkage after the silica removal steps. The $\mathrm{d}_{100}$ of SBA-15( $\perp$ ) silica and TFC carbon is 9.9 and $8.7 \mathrm{~nm}$, respectively. With the deposition of $20 \mathrm{wt}$ $\%$ PtRu nanocatalysts on TFC carbon (denoted as PtRu20/TFC sample) surface, the intensity of (100) diffraction peak decreased significantly, indicating many PtRu nanoparticles are inside the nanochannels and decrease the diffraction contrast of the loaded TFC carbon. Figure 1B shows the wide-angle XRD patterns of the samples with PtRu nanocatalysts loaded on different carbon materials. The actual loadings of PtRu in PtRu20/TFC, PtRu20/ CMK-3, and PtRu20/XC-72 samples were measured by ICPAES at 18.9, 19.7, and 20.4 wt \% total metal loading, respectively. All of the samples prepared gave rise to peaks consistent with face-centered cubic (fcc) phase of Pt crystallites. No recognizable $\mathrm{Ru}$ structure or $\mathrm{RuO}_{2}$ tetragonal phase was observed in all the samples, suggesting that the Ru was incorporated into the $\mathrm{Pt}$ fcc lattice and formed the PtRu bimetallic alloy. ${ }^{20}$ For comparison to TFC mesoporous carbon, we also used the normal CMK-3 mesoporous carbon and the commercial carbon black XC-72 as supports. The sizes of the PtRu nanoparticles, derived from peak-width of the (220) peak according to Scherrer's equation, are 4.0, 3.9, and $4.4 \mathrm{~nm}$ for PtRu20/TFC, PtRu20/CMK-3, and PtRu20/XC-72 samples, respectively. The more graphitized carbon black $\mathrm{XC}-72$, with a sharp $\mathrm{C}(002)$ diffraction peak, resulted in a larger size of PtRu nanoparticles deposited on the surface.

In Figure 2, TEM images show clearly the thin film $(\perp)$ morphology of the mesoporous silica SBA-15( $\perp)$ template (Figure 2a) and its carbon replica TFC (Figure 2b). Figure 2a gives the hexagonally arranged pores of SBA-15( $\perp)$ silica thin
TABLE 1: Nitrogen Adsorption-Desorption Characteristics over Selected Samples

\begin{tabular}{lccc}
\hline \multicolumn{1}{c}{ sample } & $\begin{array}{c}\text { BET } \\
\text { surface area } \\
\left(\mathrm{m}^{2} / \mathrm{g}\right)\end{array}$ & $\begin{array}{c}\text { pore volume } \\
\left(\mathrm{cm}^{3} / \mathrm{g}\right)\end{array}$ & $\begin{array}{c}\text { BJH pore size } \\
(\mathrm{nm})\end{array}$ \\
\hline SBA-15 $(\perp)$ silica & 693 & 1.26 & 10.0 \\
TFC & 1135 & 1.17 & 4.0 \\
CMK-3 & 1169 & 1.29 & 3.2 \\
XC-72 & 226 & 0.46 & \\
PtRu20/TFC & 926 & 0.96 & 4.0
\end{tabular}

${ }^{a}$ Total pore volume obtained from $p / p_{0}=0.99$.

film with the pores facing upward. The pore sizes are $10.0 \mathrm{~nm}$, consistent with that determined from nitrogen adsorption data (see Table 1), and the wall thickness of the nanochannel is 4.0 nm. After sucrose carbonization and HF etching, the resulting replica products (TFC or CMK-3), were composed of wellordered hexagonal arranged carbon rods (TFC shown in Figure $2 b)$. Again, the ends of rods are facing up. The pore size of the interconnected channels formed by carbon rod networks were about $4.0 \mathrm{~nm}$, consistent with wall thickness of original silica template. The TFC sample shows two Raman peaks centered at $1350 \mathrm{~cm}^{-1}$ (D band) and $1590 \mathrm{~cm}^{-1}$ (G band) (Supporting Information). The Raman peak ( $\mathrm{G}$ band) at $1590 \mathrm{~cm}^{-1}$ is mainly assigned to the in-plane displacement of carbon atoms in hexagonal carbon sheets. The peak (D band) at $1350 \mathrm{~cm}^{-1}$ is assigned to disorder in the graphitic structure. The intensity ratio $I_{\mathrm{D}} / I_{\mathrm{G}}$ is around 1.2. This reveals that some disorder forms of graphitic carbon structure present in the walls of the mesoporous carbon. Thermal gravimetric analysis (Supporting Information) of the TFC carbon shows complete weight loss, corresponding 


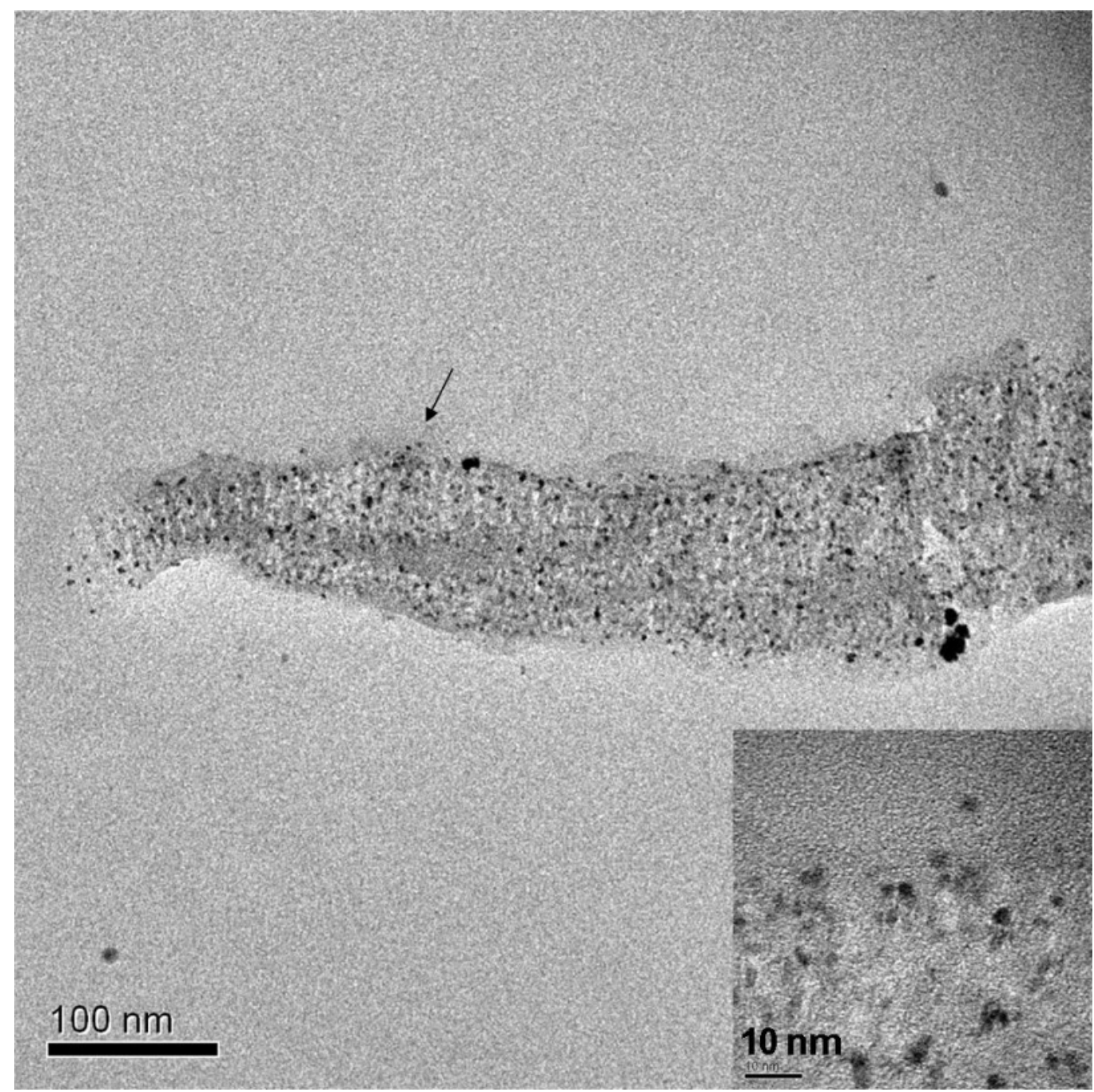

Figure 3. The microtomed TEM image of a PtRu20/TFC sample. The inset shows the enlarged graph from the arrowhead area.

to the oxidation of carbon, occurred in a temperature range between 450 and $620^{\circ} \mathrm{C}$.

In Figure 2c, the PtRu nanocatalysts were homogeneously dispersed on the TFC carbon surface and inside the rodlike structure of TFC that is still retained after PtRu deposition. The mean size of PtRu nanoparticles determined from TEM images was $4.3 \mathrm{~nm}$, as determined from Figure 2c. In addition, EDX analysis was carried out with a large number of nanoparticles at different zones of the sample to suggest the average molar ratio of $63 \% \mathrm{Pt}$ and $37 \% \mathrm{Ru}$ for the nanocatalyst composition. Figure 2d shows the SEM micrograph of the TFC carbon in which one platelet is clearly seen with perpendicular channels structure. From the thickness of the TFC, we estimate that the average channel length is $70 \mathrm{~nm}$. We should note that most of the platelets are stacked flat on the surface.

Figure 3 shows a microtomed TEM image of the PtRu20/ TFC. One can see clearly the cross section of a film structure of TFC, which shows that (1) the channels are indeed mostly perpendicular to the film and (2) most of the PtRu nanoparticles are homogeneously dispersed within the nanochannels. The inset shows that the sizes of metal nanoparticles at the arrowhead area of the channels range from 3 to $4 \mathrm{~nm}$, which is well in agreement with the XRD result. Besides, one should note that the TEM image shown in Figure $2 \mathrm{c}$ is the overall projection along the vertical direction of carbon rod structure which may lead to an impression of many larger particle or particle aggregation. Figure 3 shows that except for a few on the external surface, most of the PtRu nanoparticles are well-dispersed inside the nanochannels.

Nitrogen adsorption (Figure 4) of TFC and SBA-15 thin film shows sharply defined capillary condensation. The $\mathrm{N}_{2}$ adsorption-desorption isotherm of SBA-15 $(\perp)$ silica template is close to type IV with an $\mathrm{H}_{1}$-type hysteresis loop. However, the hysteresis loop is narrower than that of a typical SBA-15, this may be associated with the short lengths of vertical nanochannels. The TFC carbon reveals a type IV isotherm with an $\mathrm{H}_{2}$ type hysteresis loop. But the capillary condensation step is less well defined. The perpendicular channels of TFC show narrow pore size distribution, which centered at $4.0 \mathrm{~nm}$ (inset), consistent with TEM results. PtRu20/TFC sample also reveals the same mesostructure feature with TFC carbon. The BET surface area, pore volume, and BJH pore size parameters of selected samples determined from the adsorption isotherms are summarized in Table 1. The ordered mesoporous carbon materials TFC and CMK-3 have much higher surface areas $\left(>1100 \mathrm{~m}^{2} / \mathrm{g}\right.$ ) than the carbon black XC-72. After deposition of $20 \mathrm{wt} \% \mathrm{PtRu}$ nanocatalysts onto TFC carbon, the surface area $\left(926 \mathrm{~m}^{2} / \mathrm{g}\right)$ and pore volume $\left(0.96 \mathrm{~cm}^{3} / \mathrm{g}\right)$ are decreased a little while pore size remain the same $(4.0 \mathrm{~nm})$. The PtRu nanocatalysts are highly dispersed inside the vertical pore network assembled by carbon rods of TFC, as shown in Figure $2 \mathrm{c}$ and Figure 3 . The porous volume suffers only a small decrease from TFC to PtRu20/TFC (Table 1); this could be due to the fact that some small fractions of metal particles are 


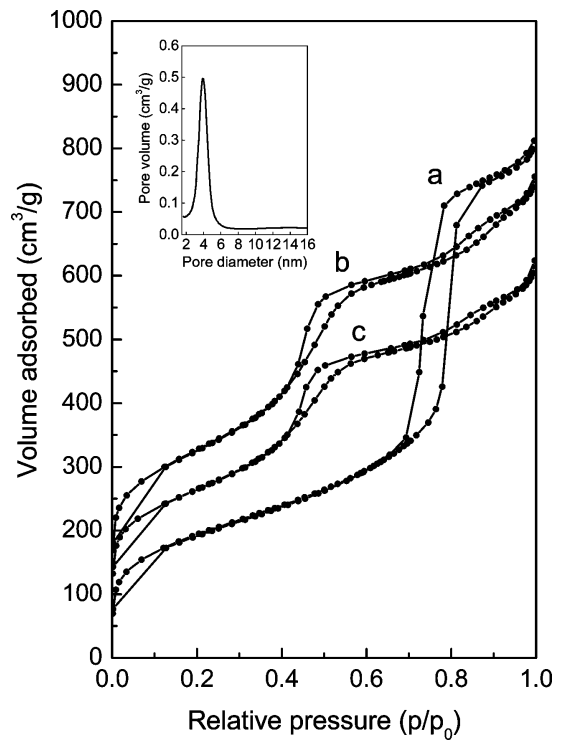

Figure 4. Nitrogen adsorption-desorption isotherms of (a) SBA-15$(\perp)$ silica, (b) TFC carbon, and (c) PtRu20/TFC. The inset shows the pore size distribution of TFC carbon.

blocking the channels. Even though TFC has nearly the same high surface area and pore volume as CMK-3 carbon, the morphology characteristics of larger pore size and shorter channel length could be of great benefits for application as fuel cell catalyst supports. The easily controllable metal nanocatalysts dispersion would increase the utilization efficiency of the nanocatalysts $^{21}$ and facile transportation of reactants and products.

To understand the surface composition and oxidation state of the PtRu catalyst, we then employ the XPS technique. In Figure 5A the Pt spectrum is deconvoluted into three components of doublets with peaks $\mathrm{Pt} 4 \mathrm{f}_{7 / 2}$ centered at binding energy $71.3,72.1$, and $73.2 \mathrm{eV}$. It suggests that $67 \%$ of $\mathrm{Pt}$ is present as $\mathrm{Pt}^{0}, 24 \%$ of two-valent $\mathrm{Pt}\left(\mathrm{Pt}^{\mathrm{II}}, \mathrm{PtO}\right.$ or $\left.\mathrm{Pt}(\mathrm{OH})_{2}\right)$, and $9 \%$ of tetravalent $\mathrm{Pt}\left(\mathrm{Pt}^{\mathrm{IV}}, \mathrm{PtO}_{2}\right)$. The low content of $\mathrm{Pt}(\mathrm{IV})$ ensures good electrocatalytic action. Figure $5 \mathrm{~B}$ shows the broad $\mathrm{Ru} 3 \mathrm{~d}_{5 / 2}$ peak centered at $281.2 \mathrm{eV}$, which overlaps with carbon $1 \mathrm{~s}$. However, the shoulder at the low-energy side may be assigned as $\mathrm{Ru}$ oxide and amorphous $\mathrm{RuO}_{x} \mathrm{H}_{y}$ species. They are found to be composed of $\mathrm{Pt}^{0}$ and $\mathrm{Ru}$ oxide as predominant species. The corresponding XPS peak areas are used to estimate the relative ratio of the metals as $\mathrm{Pt} 63 \%$ and $\mathrm{Ru} 37 \%$, in agreement with the EDX result.

We then examine the efficiency of the supported PtRu catalysts as anodic materials in DMFC by examining its cyclic voltammetry $(\mathrm{CV})$ behavior with a rotatory disk electrode (RDE). Voltages are reported relative to the reference hydrogen electrode (RHE). Figure 6 shows an obviously much higher current density for the PtRu20/TFC catalyst among the catalysts. The voltammetric features were consistent with typical electrooxidation of methanol on Pt-based bimetallics, ${ }^{22}$ namely a methanol oxidation peak during the forward scan at about $0.7 \sim 0.8 \mathrm{~V}$ and another anodic peak during the reverse scan due to the removal of incompletely oxidized carbonaceous species formed in the forward scan. However, the reverse peak was much smaller than that of the forward one, indicating the better CO resistance. The onset potentials for PtRu20/TFC, PtRu20/ CMK-3, and PtRu20/XC-72 in methanol electrochemical oxidation were $0.35,0.38$, and $0.40 \mathrm{~V}$, respectively. The new PtRu/ TFC catalyst is able to reduce the overpotential in methanol oxidation. ${ }^{23}$ It could be due to the relatively higher amount of $\mathrm{Ru}$ oxide species that formed on the surface (XPS spectra shown
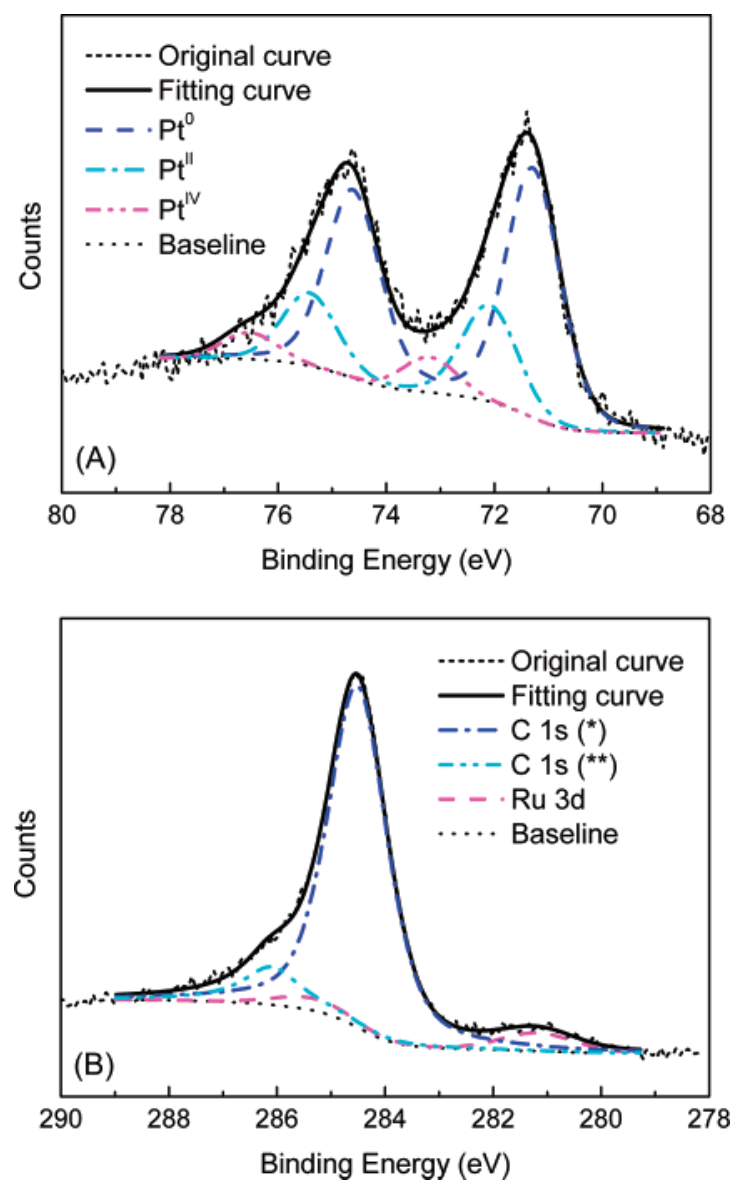

Figure 5. XPS spectra for (A) Pt 4f, (B) C 1s + Ru 3d core level of PtRu20/TFC, $(*)$ and $(* *)$ in the figure denote the graphitized and amorphous nature of TFC carbon surface, respectively.

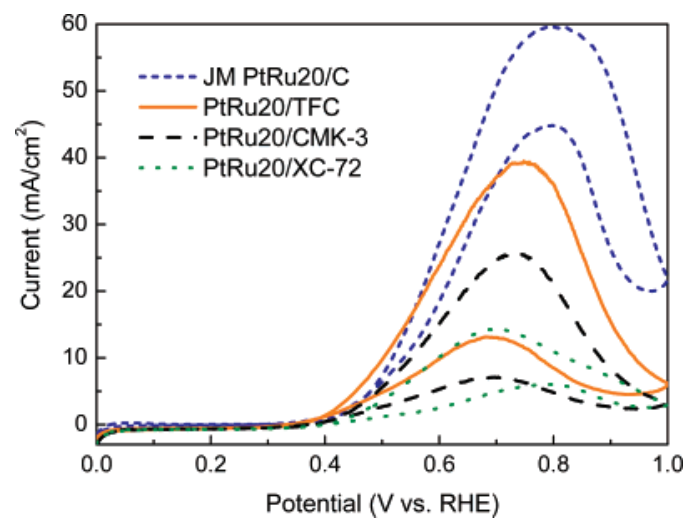

Figure 6. Cyclic voltammograms over selected samples. The curves were collected in $0.5 \mathrm{M} \mathrm{H}_{2} \mathrm{SO}_{4}$ and $1.0 \mathrm{M} \mathrm{CH}_{3} \mathrm{OH}$ solution with scan rate $10 \mathrm{mV} / \mathrm{s}$ at $60{ }^{\circ} \mathrm{C}$.

in Figure 5). Ru was well incorporated into the Pt fcc lattice with a dominant $\mathrm{Ru}$ oxide form on surface.

The ratio of the anodic peak current densities in the forward $\left(I_{\mathrm{f}}\right)$ and reverse $\left(I_{\mathrm{b}}\right)$ scans could give another measure of its catalytic performance. ${ }^{22}$ A higher $I_{\mathrm{f}} / I_{\mathrm{b}}$ ratio indicated superior oxidation activity of methanol during the anodic scan and less accumulation of carbonaceous species on the nanocatalyst surface, and thus shows better $\mathrm{CO}$ tolerance. The $I_{\mathrm{f}} / I_{\mathrm{b}}$ values were 3.01, 3.61, and 2.37 for PtRu20/TFC, PtRu20/CMK-3, and PtRu20/XC-72, respectively (Table 2). This is a rather high value compared to most literature values. ${ }^{12,22}$ Compared to a $20 \mathrm{wt}$ $\% \mathrm{PtRu} / \mathrm{C}$ catalyst of commercial Johnson Matthey sample (denoted as JM PtRu20/C, Figure 6) which gives $I_{\mathrm{f}} / I_{\mathrm{b}}=1.33$, 
TABLE 2: Methanol Electrochemical Oxidation Activities and $\mathrm{CO}_{\mathrm{ad}}$ Stripping Characteristics over Selected Samples

\begin{tabular}{|c|c|c|c|c|c|c|}
\hline sample & $\begin{array}{l}\text { current density } \\
\left(\mathrm{mA} / \mathrm{mg}_{\mathrm{PtRu}}\right) \\
\text { at } 0.5 \mathrm{~V}\end{array}$ & $\begin{array}{c}I_{\mathrm{f}} / I_{\mathrm{b}} \\
\text { value }\end{array}$ & $\begin{array}{l}\text { active PtRu } \\
\text { surface area }{ }^{a} \\
\left(\mathrm{~m}^{2} / \mathrm{g}_{\mathrm{PtRu}}\right)\end{array}$ & $\begin{array}{c}\mathrm{CO}_{\text {ad }} \text { stripping } \\
\text { peak potential } \\
\text { (V) }\end{array}$ & $\begin{array}{c}\mathrm{PtRu} \\
\text { particle size }{ }^{b} \\
(\mathrm{~nm})\end{array}$ & $\begin{array}{l}\mathrm{Pt} / \mathrm{Ru} \\
\mathrm{XPS}^{c}\end{array}$ \\
\hline PtRu20/TFC & 242.5 & 3.01 & 70.89 & 0.466 & $4.3 \pm 0.8$ & 1.71 \\
\hline PtRu20/CMK-3 & 137.5 & 3.61 & 63.15 & 0.486 & $4.1 \pm 0.8$ & 1.94 \\
\hline PtRu20/XC-72 & 88.5 & 2.37 & 43.57 & 0.493 & $4.6 \pm 0.9$ & 1.11 \\
\hline
\end{tabular}

${ }^{a}$ The active PtRu surface area was estimated assuming a monolayer of linearly adsorbed $\mathrm{CO}$ and the Coulombic charge necessary for oxidation as $420 \mu \mathrm{C} / \mathrm{cm}^{2} .{ }^{27}{ }^{b}$ The PtRu nanoparticle sizes were calculated from TEM images. ${ }^{c}$ XPS atomic ratios were estimated from Pt $4 \mathrm{f}$ and Ru $3 \mathrm{~d}$ peaks using sensitivity factors of 5.575 and 4.273 , respectively.

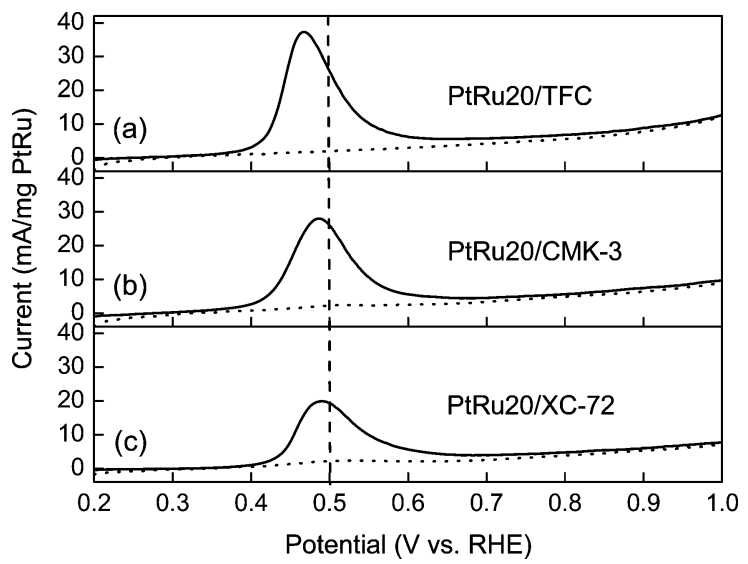

Figure 7. $\mathrm{CO}_{\mathrm{ad}}$ stripping voltammograms over selected samples. The curves were measured in $0.5 \mathrm{M} \mathrm{H}_{2} \mathrm{SO}_{4}$ solution with scan rate $10 \mathrm{mV} / \mathrm{s}$ at $60{ }^{\circ} \mathrm{C}$. Adsorption of $\mathrm{CO}$ occurred at $0.2 \mathrm{~V}$ for $15 \mathrm{~min}(-)$ and $(\cdots)$ denoted first and second anodic sweep, respectively. The dashed line set at $0.5 \mathrm{~V}$ is to show peak position clearly.

our catalysts with nanoparticle sizes of $4.0 \mathrm{~nm}$ show much better $\mathrm{CO}$ resistance. The steady-state current densities of the forward scan at $0.5 \mathrm{~V}$ of the samples are listed in Table 2 as mass current density $\mathrm{mA} / \mathrm{mg}_{\mathrm{PtRu}}$ to compare their intrinsic activities. PtRu20/ TFC gave a very high current density of $242.5 \mathrm{~mA} / \mathrm{mg}_{\mathrm{PtRu}}$, approximately three times over PtRu20/XC-72. PtRu20/TFC showed excellent performance in methanol electrooxidation as well as better $\mathrm{CO}$ tolerance. It is interesting to observe that our PtRu20/TFC catalyst of thin film morphology also gave a higher current density in comparison with the otherwise identical PtRu20/CMK-3 catalyst. The enhancement of electrocatalytic activity in using TFC as the nanocatalyst support may be resulted from the unique short pore length and thus a facile transport of the reactants and products in the methanol oxidation reactions. In addition, we have made similar measurements of a commercial JM PtRu20/C. Our PtRu20/TFC exhibited a higher current density than that of a Johnson Matthey catalyst (178.8 $\mathrm{mA} / \mathrm{mg}_{\mathrm{PtRu}}$ at $\left.0.5 \mathrm{~V}\right)$.

$\mathrm{CO}_{\mathrm{ad}}$ stripping voltammetry can provide in-situ electrochemical information of Pt-based bimetallic surfaces. ${ }^{24,25}$ Figure 7 shows the first anodic sweep of the $\mathrm{CO}_{\mathrm{ad}}$ stripping curves of the samples with 20 wt \% PtRu loaded on different carbon materials. The second anodic sweep gave the background of linear sweep voltammetry (LSV). All the samples showed sharper peaks and much lower peak potentials compared with $\mathrm{Ru}$-free $\mathrm{Pt} / \mathrm{C}$ samples in the literature. ${ }^{25,26}$ The sharp and symmetric stripping peaks are due to the more complete oxidation of the adsorbed $\mathrm{CO}_{\mathrm{ad}}$ species on the Pt sites by the hydrous oxide species on the peripheral $\mathrm{Ru}$ sites. The sample PtRu20/TFC gave higher stripping peak current as well as lower peak potential than the other two anodic materials (Table 2). The onset potentials were $0.25,0.28$, and $0.32 \mathrm{~V}$ for PtRu20/ TFC, PtRu20/CMK-3, and PtRu20/XC-72, respectively. PtRu20/ TFC shows better oxidation kinetics for the complete $\mathrm{CO}_{\mathrm{ad}}$ to

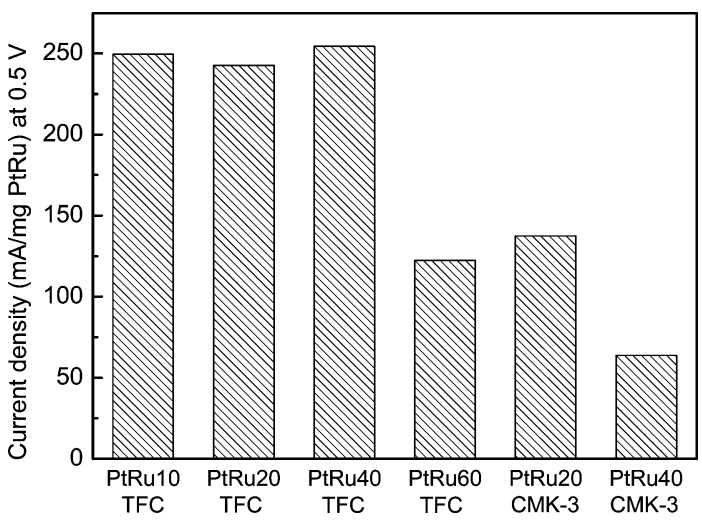

Figure 8. Histograms of mass specific current densities at $0.5 \mathrm{~V}$ for electrooxidation of methanol over selected samples. The total PtRu loadings were estimated by ICP-AES as 10.4, 18.9, 38.2, and $57.1 \mathrm{wt}$ $\%$ for PtRu10, PtRu20, PtRu40, and PtRu60 on TFC carbon, 19.7 and 38.8 wt \% for PtRu20 and PtRu40 on CMK-3, respectively.

$\mathrm{CO}_{2}$ oxidation. With the assumption of $420 \mu \mathrm{C} / \mathrm{cm}^{2}$ as the oxidation charge required for one monolayer of $\mathrm{CO}$ on a smooth Pt surface, ${ }^{27}$ the active PtRu surface areas derived from the stripping curves are listed in Table 2. With the same amount of $\mathrm{PtRu}$ loading and similar particle size distribution, it is obvious that PtRu nanocatalysts dispersed on the high surface area mesoporous carbon TFC and CMK-3 give higher active surface area of PtRu nanoparticles than the nanocatalyst on commercial carbon black, PtRu20/XC-72. As can be seen in Table 2, the higher mass current density of PtRu/TFC in methanol oxidation reaction may be partly attributed to a higher number of active surface metal sites. The PtRu20/CMK-3 has about the same active PtRu surface area as PtRu20/TFC; however, it has only half the methanol oxidation current density of the later. The CMK-3 carbon materials has smaller pore size $(3.2 \mathrm{~nm})$ and long straight channels ( $\sim 500 \mathrm{~nm}$ or more), and the transport of methanol and oxidation products may be hindered in reaching the electrocatalyst. The $\mathrm{PtRu}$ nanocatalysts inside the long channels could become inefficient in contact with the "fuel" and result in activity loss. It has been shown by Rolison and co-workers ${ }^{28}$ that electrocatalytic oxidation kinetics of methanol $(\mathrm{MeOH})$ can be much increased by using a conductive, mesoporous carbon that improves the accessibility of reactants to carbon-supported Pt catalyst.

In a traditional electrode catalyst, the lack of accessibility is often the limiting factor that current densities in fuel cells do not scale with Pt loadings. Therefore, we compare current density at different loadings of PtRu. In Figure 8, the PtRu/ TFC samples show constant and higher mass current density compared with PtRu/CMK-3 in the range of 10 40 wt \% PtRu loadings. Only in the very high loading PtRu60/TFC, one sees a drop of mass current density. On the other hand, PtRu/CMK-3 catalysts experience a loss of current density upon increase of $\mathrm{PtRu}$ loading due to long channel blockage at high metal deposition. Therefore, the short channels in TFC possess the 
advantages in increasing the utilization of PtRu nanocatalysts and thus a higher current density.

Further improvements in catalytic activity may be expected by various modifications of the electrode materials. An obvious possible improvement is to decrease the metallic particle sizes; our particle size is about the same as thechannel size. Thus many of the particles may have blocked the channels even when we greatly decreased the channel length to avoid extensive blocking. Besides, $4 \mathrm{~nm}$ is not the optimum size for catalytic activity. One could try other deposition methods to obtain a stronger confinement effect to give smaller metallic nanoparticles. On the other hand, strictly speaking, our carbon material is not graphitic; one could increase the graphitic extent of carbon ${ }^{29-31}$ to obtain better electrical conductivity or oxidize the carbon surface..$^{32,33}$

\section{Conclusions}

In this paper, we have reported a novel mesocarbon film architecture where the PtRu nanoparticles are confined within the perpendicular nanochannels which allow easier accessibility to the PtRu catalyst. The thin film morphology of the wellordered mesoporous carbon TFC gives a great potential for the development of novel electrode materials. Although periodicity in meso-structure is not by-itself important for good electrocatalyst support, ${ }^{1}$ it is this periodicity of mesoporous carbon that allows us to construct thin film of short perpendicular channel structures. The work reported here is an attempt toward high-performance fuel cell electrodes with designed nanostructures that allow improvements of the catalytic surfaces and the molecular transport at the same time with an integrated architecture.

Acknowledgment. This research was supported by a grant from the National Research Council, Taiwan. We thank Prof. H.-P. Lin and Mr. B.-C. Chen for helpful discussions in the synthesis of SBA-15( $\perp$ ) silica. We also acknowledge Dr. Y.H. Tseng for FE-SEM images.

Supporting Information Available: More results of the characterization of the mesoporous carbon TFC by Raman and TG analysis; SEM and TEM images. This material is available free of charge via the Internet at http://pubs.acs.org.

\section{References and Notes}

(1) Rolison, D. R. Science 2003, 299, 1698

(2) Yang, H. F.; Zhao, D. Y. J. Mater. Chem. 2005, 15, 1217.
(3) Lee, J.; Kim, J.; Hyeon, T. Adv. Mater. 2006, 18, 2073.

(4) Joo, S. H.; Choi, S. J.; Oh, I.; Kwak, J.; Liu, Z.; Terasaki, O.; Ryoo, R. Nature 2001, 412, 169.

(5) Hartmann, M.; Vinu, A.; Chandrasekar, G. Chem. Mater. 2005, 17,829 . 13,677

(6) Ryoo, R.; Joo, S. H.; Kruk, M.; Jaroniec, M. Adv. Mater. 2001 ,

(7) Lee, J. S.; Joo, S. H.; Ryoo, R. J. Am. Chem. Soc. 2002, 124, 1156.

(8) Kruk, M.; Jaroniec, M.; Kim, T. W.; Ryoo, R. Chem. Mater. 2003, $15,2815$.

(9) Li, Z. J.; Dai, S. Chem. Mater. 2005, 17, 1717.

(10) Chan, K. Y.; Ding, J.; Ren, J. W.; Cheng, S. A.; Tsang, K. Y. J. Mater. Chem. 2004, 14, 505.

(11) Liu, H. S.; Song, C. J.; Zhang, L.; Zhang, J. J.; Wang, H. J.; Wilkinson, D. P. J. Power Sources 2006, 155, 95.

(12) Jun, S.; Joo, S. H.; Ryoo, R.; Kruk, M.; Jaroniec, M.; Liu, Z.; Ohsuna, T.; Terasaki, O. J. Am. Chem. Soc. 2000, 122, 10712.

(13) Ding, J.; Chan, K. Y.; Ren, J. W.; Xiao, F. S. Electrochim. Acta $\mathbf{2 0 0 5}, 50,3131$.

(14) Su, F. B.; Zeng, J. H.; Bao, X. Y.; Yu, Y. S.; Lee, J. Y.; Zhao, X. S. Chem. Mater. 2005, 17, 3960.

(15) Pang, J. B.; Li, X.; Wang, D. H.; Wu, Z. W.; John, V. T.; Yang, Z. Z.; Lu, Y. F. Adv. Mater. 2004, 16, 884

(16) Chen, B. C.; Lin, H. P.; Chao, M. C.; Mou, C. Y.; Tang, C. Y. Adv. Mater. 2004, 16, 1657.

(17) Zeng, J. H.; Lee, J. Y. J. Power Sources 2005, 140, 268

(18) Takasu, Y.; Kawaguchi, T.; Sugimoto, W.; Murakami, Y. Electrochim. Acta 2003, 48, 3861.

(19) Takasu, Y.; Fujiwara, T.; Murakami, Y.; Sasaki, K.; Oguri, M.; Asaki, T.; Sugimoto, W. J. Electrochem. Soc. 2000, 147, 4421.

(20) Arico, A. S.; Creti, P.; Kim, H.; Mantegna, R.; Giordano, N.; Antonucci, V. J. Electrochem. Soc. 1996, 143, 3950.

(21) Liu, S. H.; Lu, R. F.; Huang, S. J.; Lo, A. Y.; Chien, S. H.; Liu, S. B. Chem. Commun. 2006, 3435.

(22) Liu, Z. L.; Ling, X. Y.; Su, X. D.; Lee, J. Y. J. Phys. Chem. B 2004, 108, 8234.

(23) Deivaraj, T. C.; Lee, J. Y. J. Power Sources 2005, 142, 43.

(24) Gasteiger, H. A.; Markovic, N.; Ross, P. N.; Cairns, E. J. J. Phys. Chem. 1994, 98, 617.

(25) Dinh, H. N.; Ren, X. M.; Garzon, F. H.; Zelenay, P.; Gottesfeld, S. J. Electroanal. Chem. 2000, 491, 222.

(26) Bock, C.; MacDougall, B.; LePage, Y. J. Electrochem. Soc. 2004, 151, A1269

(27) Bock, C.; Blakely, M. A.; MacDougall, B. Electrochim. Acta 2005 , $50,2401$.

(28) Anderson, M. L.; Stroud, R. M.; Rolison, D. R. Nano Lett. 2002, $2,235$.

(29) Yang, H. F.; Yan, Y.; Liu, Y.; Zhang, F. Q.; Zhang, R. Y.; Meng, Y.; Li, M.; Xie, S. H.; Tu, B.; Zhao, D. Y. J. Phys. Chem. B 2004, 108, 17320 .

(30) Kim, C. H.; Lee, D. K.; Pinnavaia, T. J. Langmuir 2004, 20, 5157.

(31) Kim, T. W.; Park, I. S.; Ryoo, R. Angew. Chem., Int. Ed. 2003, 42,4375 .

(32) de la Fuente, J. L. G.; Martinez-Huerta, M. V.; Rojas, S.; Terreros, P.; Fierro, J. L. G.; Pena, M. A. Carbon 2005, 43, 3002.

(33) Li, W. Z.; Liang, C. H.; Qiu, J. S.; Zhou, W. J.; Han, H. M.; Wei, Z. B.; Sun, G. Q.; Xin, Q. Carbon 2002, 40, 791. 